\title{
A New Equation Relating the Viscosity Arrhenius Temperature and the Activation Energy for Some Newtonian Classical Solvents
}

\author{
Aymen Messaâdi, ${ }^{1}$ Nesrine Dhouibi, ${ }^{1}$ Hatem Hamda, ${ }^{2}$ Fethi Bin Muhammad Belgacem, ${ }^{3}$ \\ Yousry Hessein Adbelkader, ${ }^{4}$ Noureddine Ouerfelli, ${ }^{5}$ and Ahmed Hichem Hamzaoui ${ }^{1}$ \\ ${ }^{1}$ Laboratoire de Valorisation des Matériaux Utiles, Centre National des Recherche en Sciences des Matériaux, B.P. 95, Borj Cedria, \\ 2050 Hammam Lif, Tunisia \\ ${ }^{2}$ Laboratoire d'Ingénierie Mathématique, Ecole Polytechnique de Tunisie, Université de Carthage, Rue El Khawarizmi, \\ B.P. 743, 2078 La Marsa, Tunisia \\ ${ }^{3}$ Department of Mathematics, Faculty of Basic Education, PAAET, 92400 Al-Ardiya, Kuwait \\ ${ }^{4}$ Department of Mathematics, Faculty of Science, University of Alexandria, Alexandria 21511, Egypt \\ ${ }^{5}$ Laboratoire Biophysique et de Technologies Médicales LR13ES04, Institut Supérieur des Technologies Médicales de Tunis, \\ Université de Tunis El Manar, 9 Avenue Dr. Zouhaier Essafi, 1006 Tunis, Tunisia
}

Correspondence should be addressed to Noureddine Ouerfelli; nouerfelli@yahoo.fr

Received 15 December 2014; Accepted 15 April 2015

Academic Editor: Demeter Tzeli

Copyright (C) 2015 Aymen Messaâdi et al. This is an open access article distributed under the Creative Commons Attribution License, which permits unrestricted use, distribution, and reproduction in any medium, provided the original work is properly cited.

\begin{abstract}
In transport phenomena, precise knowledge or estimation of fluids properties is necessary, for mass flow and heat transfer computations. Viscosity is one of the important properties which are affected by pressure and temperature. In the present work, based on statistical techniques for nonlinear regression analysis and correlation tests, we propose a novel equation modeling the relationship between the two parameters of viscosity Arrhenius-type equation, such as the energy $\left(E_{a}\right)$ and the preexponential factor $\left(A_{s}\right)$. Then, we introduce a third parameter, the Arrhenius temperature $\left(T_{A}\right)$, to enrich the model and the discussion. Empirical validations using 75 data sets of viscosity of pure solvents studied at different temperature ranges are provided from previous works in the literature and give excellent statistical correlations, thus allowing us to rewrite the Arrhenius equation using a single parameter instead of two. In addition, the suggested model is very beneficial for engineering data since it would permit estimating the missing parameter value, if a well-established estimate of the other parameter is readily available.
\end{abstract}

\section{Introduction}

Among the physicochemical properties of pure liquids and their mixtures that are constantly in demand for optimizing and designing industrial processes is viscosity. Being one of the most important factors in its own right in transport equations, nutrition, and chemical, cosmetic, and pharmaceutical industries, liquids viscosity parameters are essential for energy transference calculations and for hydraulic calculations of fluid transport [1-16]. Most cases found in industrial settings involve the difficulty posed by the nonlinear behavior of mixtures, against the mole fraction of one of the pure components constituting the corresponding binary liquid mixtures. As a result, rigorous and reliable data must be available with models that can provide a reliable estimation of the viscous behavior of mixtures [16].

The viscosity of fluids is determined both by collision among particles and by the force fields which determines interactions among molecules. The theoretical description of viscosity is therefore quite complex [16]. This is why several models have been proposed in the literature essentially based on Eyring theory or empirical or semiempirical equations that are not always applicable to a large number of mixtures [1, $2,7-10]$. On the other hand, excess thermodynamic functions (like enthalpy of hydration) and deviations of analogous nonthermodynamic functions (like viscosity) of binary liquid 
mixtures are fundamental for understanding different types of intermolecular interactions in these mixtures.

Many empirical and semiempirical models have been developed to describe the viscosity of pure liquids and binary liquid mixtures. This paper aims to contribute to describing the viscosity of pure liquids. For that, we will use statistical correlation analysis techniques for determining a relationship between the two viscosity Arrhenius parameters, allowing the reduction of the parameters number and facilitating thus calculations in engineering of fluid transport. Also, this will open a field for new theoretical concept and treatment. In addition, the suggested practical equation is useful when one of the two Arrhenius parameters data is absent. Indeed, it can be used to estimate the nonavailable value of one parameter using the information provided by the other one. In fact, the viscosity Arrhenius energy $\left(E_{a}\right)$ can be related to the enthalpy of vaporization $\left(\Delta H_{\text {vap }}^{\circ}\right)$ at the same pressure [11]. Also, for the second parameter, the preexponential factor $\left(A_{s}\right)$ can be closely related to the viscosity of the pure system in vapor state at the same studied pressure [12-15].

Recently, Ben Haj-Kacem et al. [16] proposed an empirical power law-type equation for modeling the relationship between the two parameters of viscosity Arrheniustype equation for some pure classical solvents, such as the Arrhenius energy $\left(E_{a}\right)$ or the preexponential factor $\left(\ln A_{s}\right)$. We note that this is called HajKacem-Ouerfelli equation [16] which presents good concordance only for the low and moderate viscous fluids which have no very high values of activation energy $\left(6<E_{a}<30 \mathrm{~kJ} \cdot \mathrm{mol}^{-1}\right)$ and no very low values of preexperimental factor $\left(-17<\ln \left(A_{s} / \mathrm{Pa} \cdot \mathrm{s}\right)<-10\right)$. Then, taking some mathematical considerations, we try in the present work to suggest an empirical exponential lawtype equation valid on more extended intervals, that is, for the very viscous fluids and also for the very fluid liquids like the liquefied gas $\left(5<E_{a}<60 \mathrm{~kJ} \cdot \mathrm{mol}^{-1}\right)$ and $(-25$ $\left.<\ln \left(A_{s} / \mathrm{Pa} \cdot \mathrm{s}\right)<-9\right)$. In addition, we have tried to give some physical meaning of the proposed equation parameters. We add that the suggested equation is important since it allows rewriting the viscosity Arrhenius-type equation by using a single parameter instead of two and thus it is very useful for engineering data which can permit estimating one nonavailable parameter when the second is available or can be precisely evaluated by some theories suggested in the literature.

\section{Viscosity-Temperature Dependence}

Available data of transport properties of liquids are essential for mass and heat flow. As it is one of the important properties of fluids, liquid viscosity needs to be measured or estimated given that it influences the cases of design, handling, operation of mixing, transport, injection, combustion efficiency, pumping, pipeline, atomization and transportation, and so forth. The characteristics of liquid flow depend on viscosity which is affected principally by temperature and pressure.

2.1. Theoretical Background. Due to the complex aspect of fluids, several theoretical methods for estimating viscosity are suggested in the literature [16]. Among these theories, we can cite the distribution function theory proposed by Kirkwood et al. [17], the molecular dynamic approach reported by Cummings and Evans [18], and the reaction rate theory of Eyring [19-21]. Generally, empirical and semiempirical methods provide reasonable results but they lack generality of approach, especially near or above the boiling temperature [11]. Hence, experimental data available in literature show that the liquid viscosity decreases with absolute temperature in nonlinear and concave fashion, and it is slightly dependent on low pressure.

2.2. Empirical Equations. Numerous expressions have been suggested for representing the variation of liquid viscosity, $(\eta)$ upon temperature $(T)$ through available experimental data for interpolation purpose [19-43].

We can summarize the most different forms of temperature dependence of viscosity proposed under correlation methods by the following equation [16]:

$$
\begin{aligned}
\ln (\eta)= & A+\frac{B}{T+C}+a \cdot \log T+b \cdot T+c \cdot T^{2}+\frac{D}{T^{2}} \\
& +\frac{E}{T^{3}}+\frac{F}{T^{n}} .
\end{aligned}
$$

We can classify the viscosity-temperature dependence on two great families such as liquid systems with linear or nonlinear behavior, when we plot the logarithm of dynamic viscosity $(\ln (\eta))$ against the reciprocal of absolute temperature $(1 / T)$. Furthermore, some supplement multiconstant equations (1) are proposed for numerous fluids deviating strongly to the Arrhenius behavior. We can cite the case of melting salts, glasses and metals, ionic liquids, heavy and vegetable oils, fuels and biofuels, and so forth $[11,16]$. Moreover, for the nonlinear behavior, it is found that the temperature dependence of dynamic viscosity can be fitted frequently with the Vogel-Fulcher-Tammann-type equation $[16,22-24]$, given for constants, $A_{0}, E_{0}$, and, $T_{0}$, by

$$
\ln (\eta)=\ln A_{0}+\frac{E_{0}}{R}\left(\frac{1}{T-T_{0}}\right) .
$$

In addition, for a long time, a favored theoretical base for the interpretation of viscosity was provided by the application of the transition-state theory of Arrhenius chemical kinetics to transport phenomena $[6,44]$. The exponential form is a common expression of the variation against the reciprocal absolute temperature, of some physicochemical quantities related to the transport properties such as chemical rate, diffusion, electrical conductivity, gas kinetics, and viscosity. In fact, the preexponential factor is correlated to motion, rate, disorder, speed, and entropy. Also, some theories such as kinetic theory, Maxwell-Boltzmann statistics, thermal agitation, activation, and free volume theory lead to a similar expression $[6,11]$. The second parameter $\left(E_{a}\right)$ expresses the activation energy or a gap where the studied phenomenon or property may proceed through an intermediate "transition state." 


\section{Methodology}

In addition, for the linear Arrhenius behavior, it is found that the temperature dependence of dynamic viscosity can be fitted frequently with the Arrhenius-type equation for numerous Newtonian classic solvents, which can be rewritten in the logarithmic form:

$$
\ln (\eta)=\ln \left(A_{s}\right)+\frac{E_{a}}{R}\left(\frac{1}{T}\right)
$$

where $R, E_{a}$, and $A_{s}$ are the gas constant, the Arrhenius activation energy, and the preexponential (entropic) factor of the Arrhenius equation for the liquid system, respectively.

The plot of the logarithm of shear viscosity, $\ln (\eta)$, against the reciprocal of absolute temperature $(1 / T)$ for numerous liquid systems is practically linear and the Arrhenius parameters, which are the activation energy $\left(E_{a}\right)$ and the preexponential factor $\left(\ln \left(A_{s}\right)\right)$, are thus independent of temperature over different studied temperature ranges (from 278.15 to 328.15) $\mathrm{K}$ approximately around the room temperature at constant atmospheric pressure. Using both graphical and linear least-squares fitting methods, the slope of the straight line is equal to $\left(E_{a} / R\right)$ and the intercept on the ordinate is equal to $\left(\ln A_{s}\right)$. In addition to these two main parameters, we added a third parameter $\left(T_{A}\right)$ called the Arrhenius temperature deduced from the intercept with the abscissa axis:

$$
T_{A}=\frac{-E_{a}}{R \ln \left(A_{s}\right)},
$$

which can simplify the viscosity-temperature dependence following the Eyring [5, 11, 19-21] form as

$$
\ln (\eta)=\frac{E_{a}}{R}\left(\frac{1}{T}-\frac{1}{T_{A}}\right) .
$$

Figure 1 shows how to determine graphically $E_{a} / R$ and how to proceed by extrapolation to reach the two parameters $\ln \left(A_{s}\right)$ and $T_{A}$.

3.1. Data Collection. In order to analyze an eventual correlation between the two Arrhenius parameters and to justify the proposed relationship, 75 data sets provided from literature review [11, 45-71] were taken (Table 1 ). The viscosity of different binary liquid mixtures is studied in this data set at atmospheric pressure and over different temperature ranges around the room temperature. For each binary mixture we have restricted the study only to two pure components (1) and (2) at the limits of interval of mole fraction (i.e., at $x_{1}=0$ and $x_{1}=1$ ) and plotted the logarithm of dynamic viscosity $(\ln \eta)$ versus the reciprocal absolute temperature $(1 / T)$. Then, investigation of the linear regression fit gives us these parameters values $\left(E_{a}, \ln \left(A_{s}\right)\right.$, and $\left.T_{A}\right)$. Calculated values of $\left(E_{a}, \ln \left(A_{s}\right)\right.$, and $\left.T_{A}\right)$ are reported in Table 1. For homogenous dimensions (6), we have added the Arrhenius activation temperature $\left(T^{*} / \mathrm{K}\right)$ as an additional variable for future statistical investigations:

$$
T^{*}=\frac{E_{a}}{R} .
$$

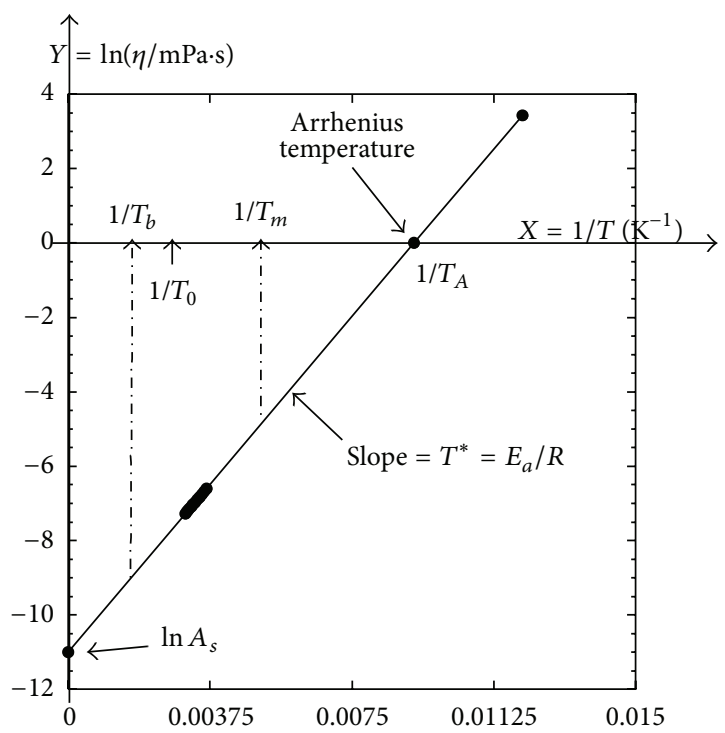

Figure 1: Graphical method for determination of the viscosity Arrhenius parameters: activation energy $\left(E_{a} / R\right)$, the logarithm of preexponential factor $\left(\ln \left(A_{s}\right)\right)(3)$, and the Arrhenius temperature $\left(T_{A}\right)(4)$. (The experimental points are delimited between the boiling point $T_{b}$ and the melting point $T_{m}$.)

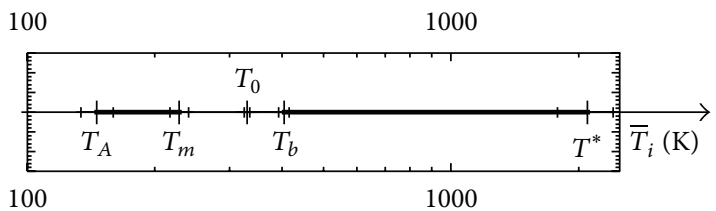

Figure 2: Classification of different mean temperatures $\left(\overline{T_{i}}\right)$ used in this statistical investigation. Great vertical bar shows average value and the small vertical bar shows delimitation of the Confidence Interval (CI).

3.2. Arrhenius Parameters and Temperatures. In order to compare the statistical values and distributions of the defined Arrhenius parameters, Table 2 presents the main descriptive statistics, such as the Arithmetic mean, Confidence Interval $(\mathrm{CI})$, standard deviation $(\sigma)$, coefficient of variation $(\mathrm{CV})$, and standard error (SE), for different defined temperatures $\left(\overline{T_{2}}\right)$ such as the Arrhenius temperature $\left(T_{A} / \mathrm{K}\right)$, the melting point $\left(T_{m} / K\right)$, the boiling point $\left(T_{b} / K\right)$, and the Arrhenius activation temperature $\left(T^{*} / \mathrm{K}\right)$.

Considering the arithmetic mean $\left(\overline{T_{\imath}}\right)$ values and the Confidence Intervals (CI) presented in Table 2, we can assume the following classification:

$$
\overline{T_{A}}<\overline{T_{m}}<\overline{T_{b}}<\overline{T^{*}},
$$

where there is no clear intersection between any consecutive (CI)-values, and Figure 2 confirms this observation.

In addition, according to the coefficient of variation (CV), the Arrhenius activation temperature $\left(T^{*}\right)$ is the most dispersed variable, contrarily to the boiling point $\left(T_{b}\right)$ which is the most homogenous. 
TABLE 1: Arrhenius parameters of some pure liquids studied at previous works, Arrhenius activation energy $E_{a}\left(\mathrm{~kJ} \cdot \mathrm{mol}^{-1}\right)$, the logarithm of the entropic factor of Arrhenius $\ln \left(A_{s} / \mathrm{Pa} \cdot \mathrm{s}\right)$, the Arrhenius temperature $\left(T_{A} / \mathrm{K}\right)$, Arrhenius activation temperature $\left(T^{*} / \mathrm{K}\right)$, the melting point $\left(T_{m} / \mathrm{K}\right)$, and the boiling point $\left(T_{b} / \mathrm{K}\right)$.

\begin{tabular}{|c|c|c|c|c|c|c|c|c|}
\hline Number & Pure component & Reference & $T^{*} / \mathrm{K}$ & $\ln A_{s}$ & $E_{a} / \mathrm{kJ} \cdot \mathrm{mol}^{-1}$ & $T_{A} / \mathrm{K}$ & $T_{b} / \mathrm{K}$ & $T_{m} / \mathrm{K}$ \\
\hline 1 & Acetone & {$[11]$} & 894.9 & -11.097 & 7.4406 & 80.643 & 329.20 & 178.45 \\
\hline 2 & Acetic acid & {$[11]$} & 1348.6 & -11.308 & 11.213 & 119.26 & 391.15 & 289.75 \\
\hline 3 & Aniline & {$[11]$} & 2405.1 & -13.564 & 19.997 & 177.32 & 457.28 & 266.85 \\
\hline 4 & Butyl alcohol & {$[11]$} & 2298.9 & -13.689 & 19.114 & 167.94 & 390.85 & 183.35 \\
\hline 5 & Carbone tetrachloride & {$[11]$} & 1242.3 & -11.152 & 10.329 & 111.39 & 349.87 & 250.23 \\
\hline 6 & Ethyl acetate & {$[11]$} & 1192.9 & -11.728 & 9.9183 & 101.72 & 350.15 & 189.55 \\
\hline 7 & Diethyl ether & {$[11]$} & 904.48 & -11.446 & 7.5203 & 79.021 & 307.75 & 156.85 \\
\hline 8 & n-Heptane & {$[11]$} & 1036.7 & -11.302 & 8.6196 & 91.723 & 371.15 & 182.55 \\
\hline 9 & n-Pentane & {$[11]$} & 733.64 & -10.886 & 6.0998 & 67.393 & 309.25 & 143.45 \\
\hline 10 & Toluene & {$[11]$} & 1085.2 & -11.135 & 9.0229 & 97.461 & 383.75 & 180.15 \\
\hline 11 & $m$-Xylene & {$[11]$} & 1052.2 & -10.975 & 8.7485 & 95.872 & 412.25 & 225.35 \\
\hline 12 & n-Octanol & {$[45]$} & 3001.4 & -14.945 & 24.955 & 200.83 & 468.15 & 257.15 \\
\hline 13 & Propylene glycol & {$[46]$} & 5744.8 & -22.128 & 47.765 & 259.62 & 461.35 & 214.15 \\
\hline 14 & Butane-1,2-diol & [47] & 5281.1 & -20.681 & 43.910 & 255.36 & 465.15 & 159.15 \\
\hline 15 & Butane-1,4-diol & [47] & 4012.2 & -16.210 & 33.359 & 247.51 & 503.15 & 293.15 \\
\hline 16 & Propylene glycol & {$[48]$} & 4516.3 & -18.266 & 37.551 & 247.25 & 461.35 & 214.15 \\
\hline 17 & 1,2-Butanediol & {$[48]$} & 5624.3 & -21.857 & 46.763 & 257.32 & 465.15 & 159.15 \\
\hline 18 & 1,2-Butanediol & {$[48]$} & 5524.5 & -21.510 & 45.933 & 256.84 & 465.15 & 159.15 \\
\hline 19 & 1,4-Butanediol & {$[48]$} & 4093.3 & -16.485 & 34.033 & 248.31 & 503.15 & 293.15 \\
\hline 20 & 1,4-Butanediol & {$[48]$} & 4077.7 & -16.438 & 33.904 & 248.07 & 503.15 & 293.15 \\
\hline 21 & Benzene & {$[11]$} & 1315.8 & -11.812 & 10.940 & 111.39 & 353.15 & 278.65 \\
\hline 22 & Chlorobenzene & {$[11]$} & 1047.5 & -10.695 & 8.7094 & 97.939 & 405.15 & 228.15 \\
\hline 23 & Ethylbenzene & {$[11]$} & 1095.8 & -11.027 & 9.1110 & 99.375 & 409.15 & 178.15 \\
\hline 24 & $o$-Xylene & {$[11]$} & 1183.0 & -11.145 & 9.8360 & 106.14 & 417.15 & 248.65 \\
\hline 25 & N,N-Dimethylacetamide & [49] & 1173.7 & -10.914 & 9.7590 & 107.54 & 438.55 & 253.15 \\
\hline 26 & Formamide & {$[49]$} & 1973.7 & -12.442 & 16.410 & 158.63 & 483.15 & 275.65 \\
\hline 27 & N,N-Dimethylformamide & [49] & 1088.8 & -10.780 & 9.0530 & 101.00 & 425.00 & 212.15 \\
\hline 28 & N,N-Dimethylacetamide & {$[50]$} & 1133.7 & -10.896 & 9.4260 & 104.05 & 438.55 & 253.15 \\
\hline 29 & Water & {$[50]$} & 1865.4 & -13.284 & 15.510 & 140.42 & 373.15 & 273.15 \\
\hline 30 & 2-Methoxyethanol & {$[50]$} & 1826.3 & -12.602 & 15.185 & 144.93 & 397.65 & 188.15 \\
\hline 31 & N,N-Dimethylacetamide & {$[51]$} & 1178.3 & -10.934 & 9.7973 & 107.77 & 438.55 & 253.15 \\
\hline 32 & 2-Ethoxyethanol & {$[51]$} & 1900.7 & -12.682 & 15.803 & 149.87 & 408.15 & 183.15 \\
\hline 33 & Water & {$[52]$} & 1914.7 & -13.443 & 15.920 & 142.43 & 373.15 & 273.15 \\
\hline 34 & 1,4-Dioxane & {$[52]$} & 1522.6 & -11.853 & 12.660 & 128.47 & 374.15 & 284.15 \\
\hline 35 & Water & [53] & 1894.2 & -13.383 & 15.749 & 141.54 & 373.15 & 273.15 \\
\hline 36 & Isobutyric acid & [53] & 1338.1 & -11.200 & 11.126 & 119.48 & 426.65 & 226.15 \\
\hline 37 & Water & {$[54]$} & 1856.2 & -13.232 & 15.433 & 140.28 & 373.15 & 273.15 \\
\hline 38 & Ethanol & {$[54]$} & 1588.1 & -12.166 & 13.204 & 130.50 & 351.15 & 159.15 \\
\hline 39 & Water & {$[55]$} & 1881.1 & -13.334 & 15.640 & 141.07 & 373.15 & 273.15 \\
\hline 40 & Methanol & {$[55]$} & 1194.8 & -11.528 & 9.9340 & 103.64 & 337.75 & 175.55 \\
\hline 41 & Dimethylsulfoxide & {$[56]$} & 1690.8 & -11.872 & 14.058 & 142.42 & 462.15 & 290.65 \\
\hline 42 & $p$-Xylene & {$[56]$} & 1009.3 & -10.761 & 8.3920 & 93.800 & 411.15 & 285.65 \\
\hline 43 & Dimethylsulfoxide & {$[57]$} & 1723.9 & -12.002 & 14.333 & 143.63 & 462.15 & 290.65 \\
\hline 44 & $o$-Xylene & [57] & 1151.4 & -11.044 & 9.5730 & 104.26 & 417.15 & 248.65 \\
\hline 45 & Water & [58] & 2006.6 & -13.742 & 16.684 & 146.02 & 373.15 & 273.15 \\
\hline
\end{tabular}


TABle 1: Continued.

\begin{tabular}{|c|c|c|c|c|c|c|c|c|}
\hline Number & Pure component & Reference & $T^{*} / \mathrm{K}$ & $\ln A_{s}$ & $E_{a} / \mathrm{kJ} \cdot \mathrm{mol}^{-1}$ & $T_{A} / \mathrm{K}$ & $T_{b} / \mathrm{K}$ & $T_{m} / \mathrm{K}$ \\
\hline 46 & 1,4-Dioxane & {$[58]$} & 1403.5 & -11.430 & 11.669 & 122.78 & 374.15 & 284.15 \\
\hline 47 & Ethylene glycol & {$[58]$} & 3601.1 & -16.146 & 29.941 & 223.03 & 470.15 & 260.15 \\
\hline 48 & Triethyl amine & {$[59]$} & 987.68 & -11.248 & 8.2120 & 87.810 & 361.95 & 158.15 \\
\hline 49 & Water & {$[60]$} & 1898.6 & -13.389 & 15.786 & 141.80 & 373.15 & 273.15 \\
\hline 50 & Glycerol & {$[61]$} & 7169.2 & -24.143 & 59.608 & 296.95 & 455.15 & 293.15 \\
\hline 51 & TEGMME* & {$[62]$} & 2555.2 & -13.638 & 21.245 & 187.36 & 395.15 & 229.15 \\
\hline 52 & n-Heptane & {$[63]$} & 1725.2 & -12.613 & 14.344 & 136.78 & 371.15 & 182.15 \\
\hline 53 & 1-Propanol & {$[64]$} & 2139.9 & -13.415 & 17.792 & 159.51 & 370.15 & 149.15 \\
\hline 54 & 2-Propanol & {$[64]$} & 2640.0 & -15.032 & 21.950 & 175.63 & 355.15 & 183.65 \\
\hline 55 & t-Butanol & {$[64]$} & 3852.2 & -18.476 & 32.029 & 208.50 & 355.55 & 298.84 \\
\hline 56 & Allyl alcohol & {$[64]$} & 1840.8 & -12.866 & 15.305 & 143.07 & 370.15 & 144.15 \\
\hline 57 & Propargyl alcohol & {$[64]$} & 1816.7 & -12.607 & 15.105 & 144.10 & 387.65 & 220.15 \\
\hline 58 & Dimethylsulfoxide & {$[65]$} & 1409.7 & -10.975 & 11.721 & 128.44 & 462.15 & 290.65 \\
\hline 59 & Benzene & {$[65]$} & 1798.7 & -13.254 & 14.955 & 135.71 & 353.15 & 278.65 \\
\hline 60 & Ethylbenzene & {$[65]$} & 1022.5 & -10.807 & 8.5016 & 94.617 & 409.15 & 178.15 \\
\hline 61 & Chlorobenzene & {$[65]$} & 954.13 & -10.406 & 7.9331 & 91.687 & 405.15 & 228.15 \\
\hline 62 & Bromobenzene & {$[65]$} & 2017.1 & -13.450 & 16.771 & 149.98 & 429.15 & 242.15 \\
\hline 63 & 1,4-Dioxane & {$[66]$} & 1452.2 & -11.607 & 12.074 & 125.11 & 374.15 & 284.15 \\
\hline 64 & Ethanol & {$[66]$} & 1885.9 & -12.997 & 15.680 & 145.10 & 351.15 & 159.15 \\
\hline 65 & 2-Propanol & {$[66]$} & 3058.5 & -16.403 & 25.430 & 186.46 & 355.15 & 183.65 \\
\hline 66 & Isoamyl alcohol & {$[66]$} & 2602.7 & -14.322 & 21.640 & 181.72 & 403.15 & 156.15 \\
\hline 67 & 3-Amino-1-propanol & {$[66]$} & 4336.9 & -18.036 & 36.059 & 240.46 & 458.65 & 284.15 \\
\hline 68 & Water & {$[67]$} & 1872.4 & -13.307 & 15.568 & 140.70 & 373.15 & 273.15 \\
\hline 69 & 2-Methoxyethanol & {$[67]$} & 1744.4 & -12.662 & 14.504 & 137.77 & 397.65 & 188.15 \\
\hline 70 & N-Methylacetamide & {$[67]$} & 2300.6 & -13.155 & 19.128 & 174.88 & 478.15 & 300.15 \\
\hline 71 & Propylene carbonate & {$[68]$} & 1706.9 & -11.729 & 14.192 & 145.53 & 513.15 & 218.15 \\
\hline 72 & 1,2-Diethoxyethane & [69] & 910.34 & -10.819 & 7.5690 & 84.142 & 394.15 & 199.15 \\
\hline 73 & Acetonitrile & {$[70]$} & 840.64 & -10.793 & 6.9895 & 77.885 & 354.65 & 222.15 \\
\hline 74 & Methanol & {$[71]$} & 1226.5 & -11.629 & 10.198 & 105.47 & 337.75 & 175.55 \\
\hline 75 & Tetrahydrofuran & {$[71]$} & 810.42 & -10.393 & 6.7382 & 77.977 & 339.15 & 165.15 \\
\hline
\end{tabular}

*TEGMME is an abbreviation of triethylene glycol monomethyl ether.

TABLE 2: Descriptive statistics on temperatures' parameters: arithmetic mean $\left(\overline{T_{i}}\right)$, Confidence Interval $(\mathrm{CI})$, standard deviation $(\sigma)$, coefficient of variation (CV), and standard error (SE).

\begin{tabular}{lccccc}
\hline Parameters & $\overline{T_{i}} / \mathrm{K}$ & $\mathrm{CI}$ & $\sigma$ & $\mathrm{CV}(\%)$ & $\mathrm{SE}$ \\
\hline$T_{A}$ & 146.25 & $133.73-158.76$ & 54.189 & 37.05 & 6.2572 \\
$T_{m}$ & 228.57 & $216.99-240.15$ & 50.142 & 21.94 & 5.7899 \\
$T_{b}$ & 403.63 & $392.10-415.16$ & 49.929 & 12.37 & 5.7653 \\
$T^{*}$ & 2096.1 & $1781.8-2410.4$ & 1361.0 & 64.93 & 157.16 \\
\hline
\end{tabular}

\section{Correlations Investigation}

4.1. Correlation between the Arrhenius Temperature and the Activation Energy. Initially, we started to study the direct mutual correlation between the defined Arrhenius parameters $T_{A}, \ln A_{s}$, and $E_{a}$. Figure 3 gives graphical representation of the pairwise correlations for some pure Newtonian classical solvents determined by couples of components from some binary liquid mixtures studied in previous works [11, 4571]. We deduce that strong correlation may exist between the three parameters. In addition, through the feeble curvature, the scatter plots forms show that linear correlation may exist between $E_{a}$ and $\ln \left(A_{s}\right)$ (Figure 3(b)). However, nonlinear correlation seems to be more adequate between $T_{A}$ and $\ln \left(A_{s}\right)$ or $E_{a}$ (Figures 3(a) and 3(c)).

In fact, the distribution's dispersion observed in Figure 3(a) and indicating weak nonlinear correlation between the logarithm of the preexponential factor $\ln \left(A_{s} / \mathrm{Pa} \cdot \mathrm{s}\right)$ and the Arrhenius temperature $T_{A}(\mathrm{~K})$ can permit us to write $\lim _{T_{A} \rightarrow 0} \ln \left(A_{s}\right) \neq 0$. Also, Figure 3(b) presenting pseudolinear correlation between the Arrhenius activation energy $E_{a}\left(\mathrm{~kJ} \cdot \mathrm{mol}^{-1}\right)$ and the logarithm of the preexponential factor $\ln \left(A_{s} / \mathrm{Pa} \cdot \mathrm{s}\right)$ can also permit us to write $\lim _{E_{a} \rightarrow 0} \ln \left(A_{s}\right) \neq 0$. In addition, Figure 3(c) showing nonlinear strong correlation between the Arrhenius activation energy $E_{a}\left(\mathrm{~kJ} \cdot \mathrm{mol}^{-1}\right)$ and the Arrhenius temperature $T_{A}(\mathrm{~K})$ permits us to conclude that probably the Arrhenius 


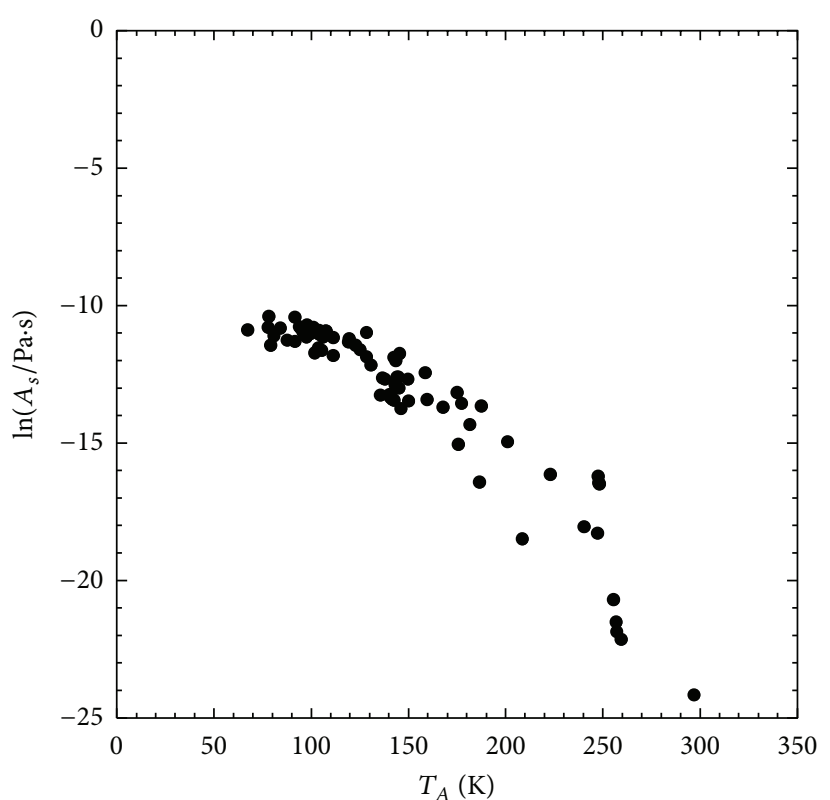

- $\ln A_{s}$

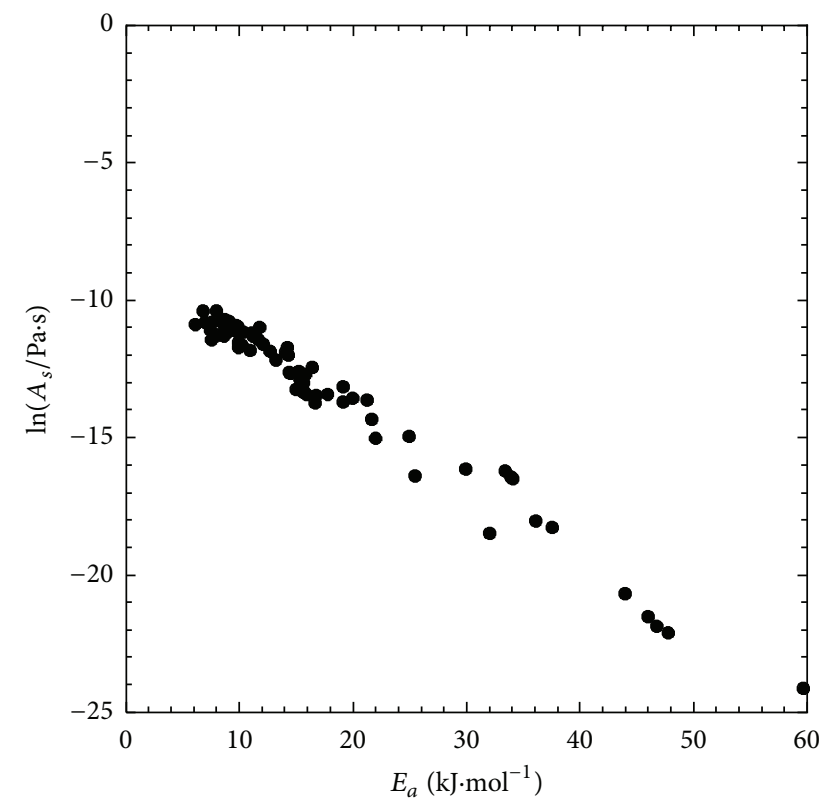

- $\ln A_{s}$

(a)

(b)

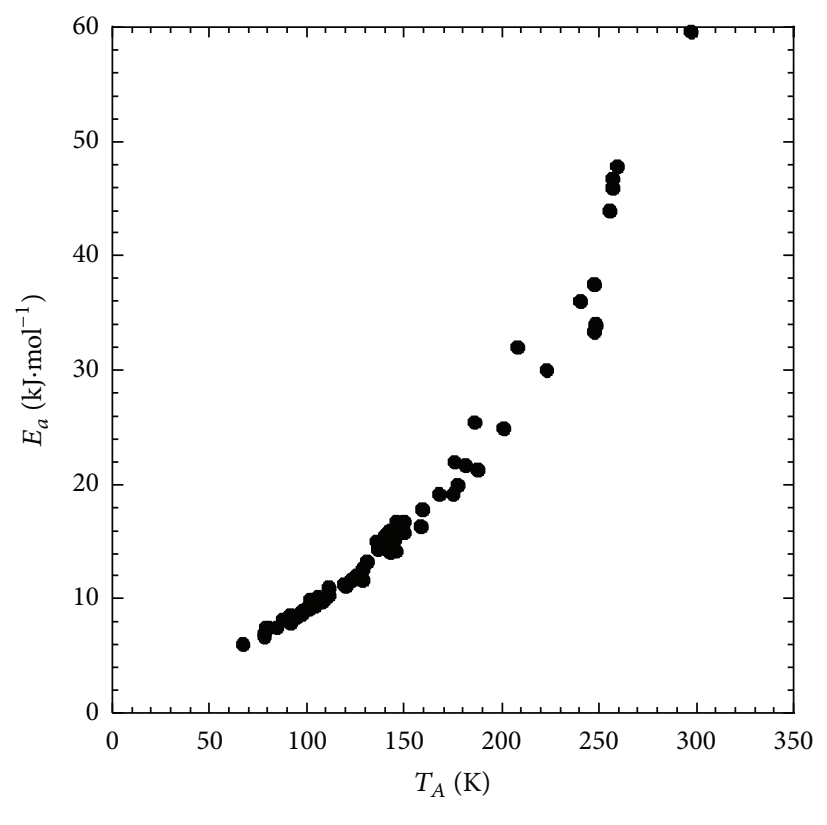

- $E_{a}$

(c)

FIGURE 3: Scatter plots for pairwise correlations between Arrhenius parameters.

temperature $\left(T_{A}\right)$ and the activation energy $\left(E_{a}\right)$ tend towards zero at the same time, and $\left(T_{A}\right)$ cannot exceed a certain limit value $\left(T_{A \text { lim }}\right)$ when taking infinite value.

4.2. The Proposed Equation Model. The feeblest dispersion in the distribution in Figure 3(c) leads us to start modeling the dependence between $\left(E_{a}\right)$ and $\left(T_{A}\right)$. Due to the limits' discussion in the precedent section (Section 4.1) we propose the following equation which respects the observed boundary conditions:

$$
E_{a}=-\alpha \cdot \ln \left(1-\beta \cdot T_{A}\right),
$$

where $\alpha$ and $\beta$ are positive constants. In fact, when we neglect the feeble curvature of the plot of $\left(E_{a}\right)$ as a function of ( $\ln A_{s}$ ) in Figure 3(b), a linear correlation gives the straight line equation as $\left(E_{a}=-31.3576-0.24845 \ln A_{s}\right)$ with 
TABLE 3: Estimation results of proposed nonlinear regressions ((8) and (11)) between Arrhenius parameters.

\begin{tabular}{lccccccrr}
\hline Equation & $\chi^{2}$ & $R^{2}$ & $\alpha / \mathrm{kJ} \cdot \mathrm{mol}^{-1}$ & Error & $\beta / \mathrm{K}^{-1}$ & Error & $\gamma / \mathrm{mol}^{-\mathrm{kJ}} \mathrm{J}^{-1}$ & Error \\
\hline$(8)$ & 3.13539 & 0.97585 & 27.15289 & 0.73539 & 0.00303 & 0.00004 & - & - \\
$(11)$ & 6.2603 & 0.95111 & 27.15289 & 0 & 0.00303 & 0 & 0.01954 \\
$(11)$ & 5.11155 & 0.96062 & 26.13792 & 0.26758 & 0.00303 & 0 & 0.02229 & 0.00095 \\
\hline
\end{tabular}

an $R$-square equal to 0.9729 . In this case we can conclude that (Figure 3(b)) $\lim _{E_{a} \rightarrow 0} \ln \left(A_{s}\right) \neq 0$ and $\lim _{E_{a} \rightarrow \infty} \ln \left(A_{s}\right)=$ $-\infty$. Given the expression of the Arrhenius temperature $\left(T_{A}\right)$ of (4), $T_{A}=-E_{a} / R \ln \left(A_{s}\right)$, and $E_{a}=-R \cdot T_{A} \ln \left(A_{s}\right)$, we can conclude that $\lim _{T_{A} \rightarrow 0} E_{a}=0$ and $T_{A}$ cannot exceed a limiting value $\left(T_{\lim }\right)$ when $\left(E_{a}\right)$ tends to infinity: $\lim _{T_{A} \rightarrow T_{A l i m}} E_{a}=+\infty$. In addition, if we consider that the quasilinear dependence continues with the same slope at the infinity we can estimate this limit around $T_{\lim } \approx$ $441.2 \mathrm{~K}$. Then, we justify that the mathematical function $E_{a}=f\left(T_{A}\right)$ passes through the origin and adopts a vertical asymptote when the $T_{A}$-value tends to $T_{\lim }$ (Figure $3(\mathrm{c})$ ). In this context, we proposed (8). Table 3 summarizes the nonlinear regression where $\left(\chi^{2}\right)$ and $\left(R^{2}\right)$ are the Chi-square and the $R$-square, respectively.

Considering (8) we can write the reciprocal expression as

$$
T_{A}=\frac{1-e^{-E_{a} / \alpha}}{\beta} .
$$

Also, considering (4) and (9), we can write

$$
\ln \left(A_{s}\right)=\frac{-\beta \cdot E_{a}}{R \cdot\left[1-e^{-E_{a} / \alpha}\right]} .
$$

In the reciprocal expression of (10), when $E_{a}$ becomes the dependent variable and $\ln A_{s}$ the independent one, it seems to be hard to find analytical expression because of the linear form of $E_{a}$ in the numerator and the exponential one in the denominator. So, regarding the pseudomonotonous dependence between $E_{a}$ and $\ln A_{s}$ shown in Figure 3(a) we can suggest similar expression for the inverse situation:

$$
E_{a}=-\frac{(R / \beta) \ln \left(A_{s}\right)+\alpha}{\left[1-e^{(R \cdot \gamma) / \beta \cdot \ln \left(A_{s}\right)},\right.},
$$

when $\gamma$ is an additional adjusted parameter. Table 3 summarizes the nonlinear regression where $\alpha$ is considered fixed or free variable.

Considering the expression of (9) and the fact that the Arrhenius temperature $T_{A}$ cannot exceed a limiting value $\left(T_{\lim }\right)$ when $E_{a}$ tends to infinity, $\lim _{T_{A} \rightarrow T \lim } E_{a}=+\infty$, we can conclude that $T_{\text {lim }}=1 / \beta$ which can be denoted by $T_{0}$. This limiting Arrhenius temperature has the following value for the present study: $T_{0}=330.03 \pm 4.36 \mathrm{~K}$. Comparing this value and the set of temperature averages $\left(\overline{T_{i}}\right)$ presented in Table 2 and Figure 2, we can conclude that $T_{0}$ is probably correlated with the boiling temperature $\left(T_{b}\right)$. In fact, in previous works we observed that the mean $T_{A}$-values for all the studied binary mixtures are near and less than the boiling temperatures $\left(T_{\mathrm{bi}}\right)$ of the corresponding constituting pure components or near temperatures related to their isobaric vapor-liquid phase diagrams [12-15, 52, 72-74]. To this end, and to give out more physical significances for parameters, we will explicit the term of the limiting Arrhenius temperature $\left(T_{0}\right)$ in the expressions of equations; we will explicit the term of $T_{0}$ in the expressions of (8), (9), (10), and (11) and rewrite them with three adjustable parameters $\left(T_{0}, \alpha_{0}\right.$, and $\left.\gamma_{0}\right)$ as follows:

$$
\begin{aligned}
E_{a} & =-\alpha_{0} R T_{0} \cdot \ln \left(1-\frac{T_{A}}{T_{0}}\right), \\
T_{A} & =\left[1-e^{-E_{a} / \alpha_{0} R T_{0}}\right] \cdot T_{0}, \\
\ln \left(A_{s}\right) & =\frac{-E_{a}}{R T_{0} \cdot\left[1-e^{-E_{a} / \alpha_{0} R T_{0}}\right]}, \\
E_{a} & =-\frac{R T_{0} \cdot\left[\ln \left(A_{s}\right)+\alpha_{0}\right]}{\left[1-e^{\left(R T_{0} \cdot \ln \left(A_{s}\right)\right) / \gamma_{0}}\right]},
\end{aligned}
$$

where $R$ is the perfect gas constant, $T_{0}$ is the limiting Arrhenius temperature, and $\left(\alpha_{0}=9.894 \pm 0.536\right)$ and $\left(\gamma_{0}=\right.$ $44.86 \pm 1.91) 10^{3}$ are two dimensionless constants.

According to the precedent modifications introduced into (12) to (15), the Arrhenius-type equation becomes an equation with only one parameter $\left(E_{a}\right.$ or $\left.\ln A_{s}\right)$ :

$$
\ln (\eta)=\frac{-E_{a}}{R T_{0} \cdot\left[1-e^{-E_{a} / \alpha_{0} R T_{0}}\right]}+\frac{E_{a}}{R} \cdot\left(\frac{1}{T}\right)
$$

or

$$
\ln (\eta)=\ln \left(A_{s}\right)-\frac{R T_{0} \cdot\left[\ln \left(A_{s}\right)+\alpha_{0}\right]}{\left[1-e^{\left(R T_{0} \cdot \ln \left(A_{s}\right)\right) / \gamma_{0}}\right]} \cdot\left(\frac{1}{T}\right)
$$

where $R=8.3144721 \mathrm{~J} \cdot \mathrm{mol}^{-1},\left(T_{0}=330.03 \pm 4.36\right) \mathrm{K},\left(\alpha_{0}=\right.$ $9.894 \pm 0.536)$, and $\left(\gamma_{0}=44.86 \pm 1.91\right) 10^{3}$.

Figure 4 shows the experimental activation energy $\left(E_{a}\right)_{\exp }$ and the entropic factor $\left(\ln A_{s}\right)_{\exp }$ in comparison with the estimated ones $\left(E_{a}\right)_{\exp }$ and $\left(\ln A_{s}\right)_{c a l c}$, respectively. Data are in close approximation to the corresponding $E_{a}$-values and $\ln A_{s}$-values estimated from (15) and (14). Going to the very low and very high values of the activation energy $\left(E_{a}\right)$ and the entropic factor $\left(\ln A_{s}\right)$, Figure 4 shows that the gap between experimental and estimated values is indicating an acceptable slight discrepancy. The goodness of this result is supported by the $R$-squared value $(0.9606)$ and by the mean squared errors (MES) value of $\left(710^{-3}\right)$. The reliable $R$-squared value suggests that the experimental data is well fitted by the current proposed model. 


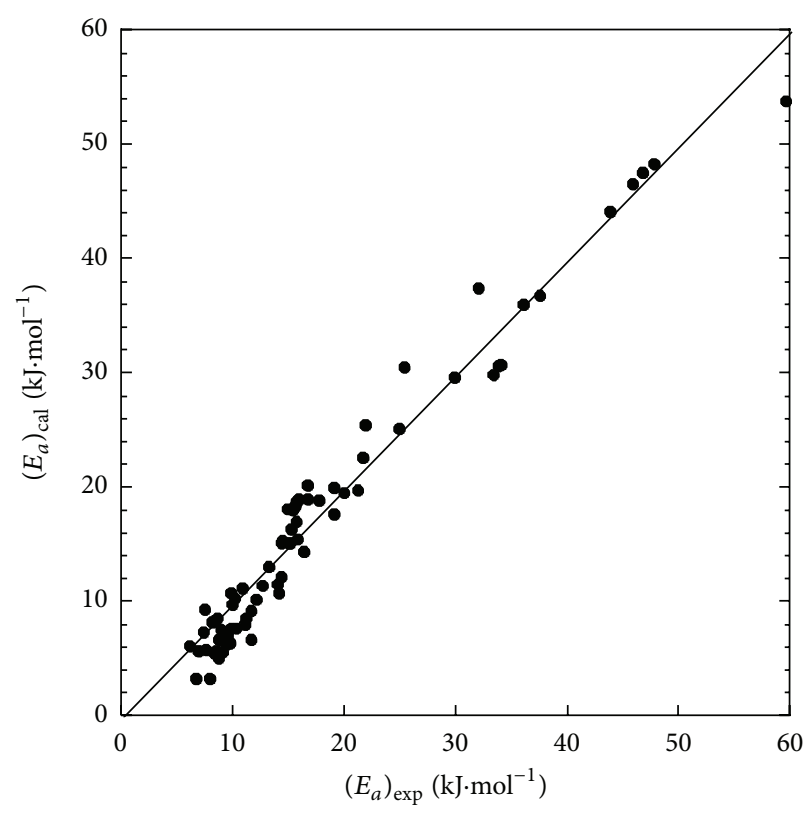

(a)

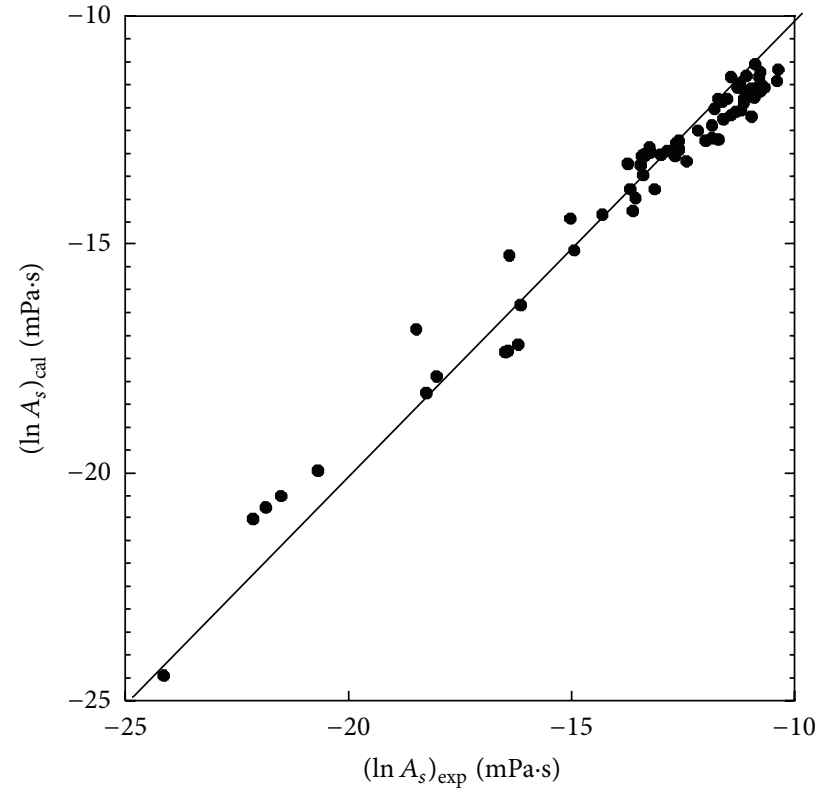

(b)

Figure 4: (a) Comparison between the experimental activation energy values $\left(E_{a}\right)_{\exp }$ and the estimated ones $\left(E_{a}\right)_{\text {calc }}$ from (15); (b) comparison between the experimental entropic factor values $\left(\ln A_{s}\right)_{\exp }$ and the estimated ones $\left(\ln A_{s}\right)_{\text {calc }}$ from (14).

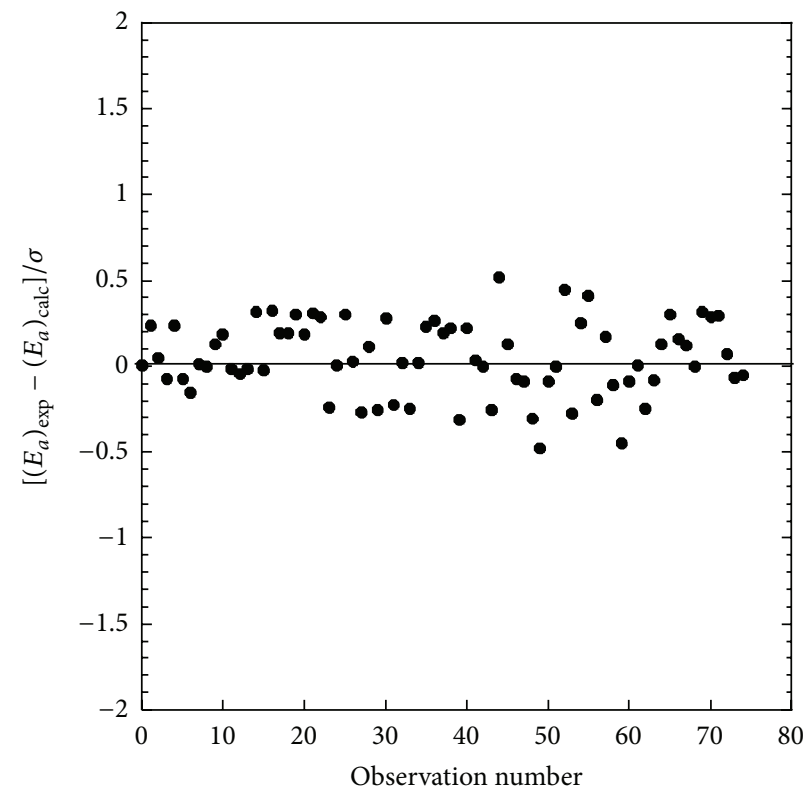

(a)

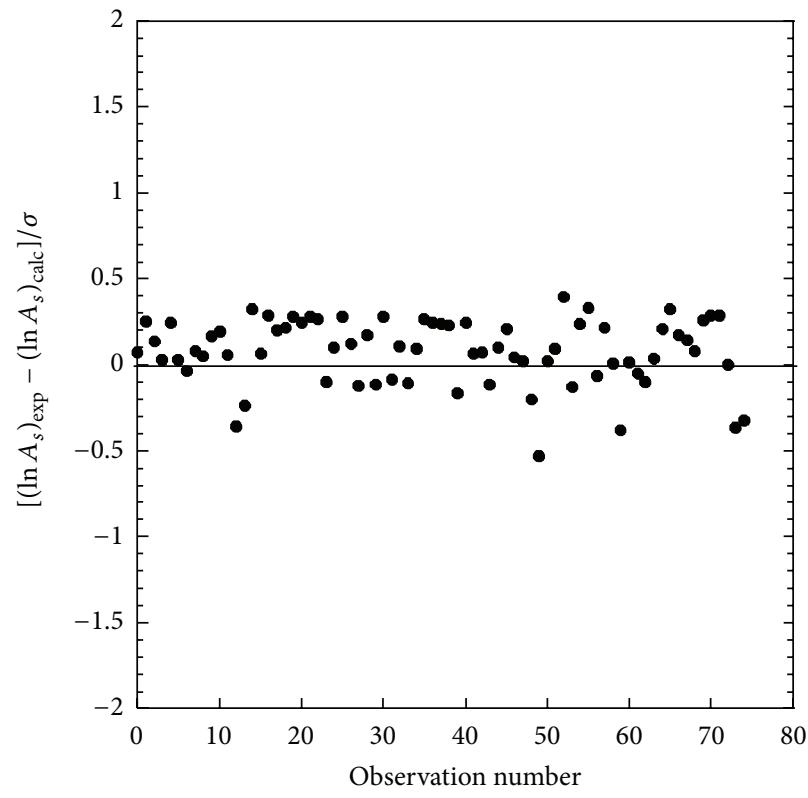

(b)

FIGURE 5: Normalized deviation plot related to (a) the activation energy $\left[\left(E_{a}\right)_{\exp }-\left(E_{a}\right)_{\text {calc }}\right] / \sigma$ and (b) the entropic factor $\left[\left(\ln A_{s}\right)_{\exp }-\right.$ $\left.\left(\ln A_{s}\right)_{\text {calc }}\right] / \sigma$ against the number of observations (solvent).

In addition, Figure 5 shows the normalized estimation errors of the experimental activation energy $\left(E_{a}\right)$ and the experimental entropic factor $\left(\ln A_{s}\right)$, respectively. The figures confirm the precedent result about the good quality of estimators. Indeed, the figures show little normalized variation between experimental and estimated values of parameters except for the observations which have very high or very low values of experimental activation energy $\left(E_{a}\right)$ and entropic factor $\left(\ln A_{s}\right)$ that is very close to the boundaries of the studied interval. We conclude that the proposed equation presents good concordance from the low to the high viscous fluids and presents very feeble discrepancy in the two limits of 
the studied intervals $\left(5<E_{a}<60 \mathrm{~kJ} \cdot \mathrm{mol}^{-1}\right)$ for the activation energy and $\left(-25<\ln \left(A_{s} / \mathrm{Pa} \cdot \mathrm{s}\right)<-9\right)$ for the preexperimental factor.

\section{Conclusion}

Based on experimental data of viscosities for some pure solvents and about 34 Newtonian binary liquid mixtures over different temperature ranges at atmospheric pressure reported in the literature [11,45-71], we have determined values of the two viscosity Arrhenius parameters such as the activity energy $\left(E_{a}\right)$ and the entropic factor $\left(\ln \left(A_{s}\right)\right)$ for 75 sets of the pure liquid components constituting the precedent binary mixtures at infinite dilution (i.e., at molar fraction equal to 0 or 1 ). Practically all of them obey the linear Arrhenius behavior.

In the present work, we have used statistical methods to analyze eventual correlation between the Arrhenius parameters for the same pure liquids. We found that there is significant statistical nonparametric correlation between the activity energy $\left(E_{a}\right)$ and the entropic factor $\left(\ln \left(A_{s}\right)\right)$, as well as the derived parameter called Arrhenius temperature $\left(T_{A}\right)$. Results showed that the model which best fits the relationship between the defined Arrhenius parameters is a logarithmic type correlating the activation energy $\left(E_{a}\right)$ to the Arrhenius temperature $T_{A}(\mathrm{~K})$. Hence, for programming and calculating facilities in hydraulic calculations of fluid transportations and for energy transfer calculations [1-11], we have reduced the model using single variable without losing significant accuracy.

So, in the present work, we proposed an equation for modeling the relationship ((14) or (15)) between the two parameters of viscosity Arrhenius-type equation, such as the Arrhenius energy $\left(E_{a}\right)$ or the preexponential factor $\left(\ln \left(A_{s}\right)\right)$. Moreover, the proposed equation allows redefining the Arrhenius equation by using a single parameter ((16) or (17)) instead of two ones (3) by using experimental viscosity values at several temperatures for 75 pure liquids taken from the literature $[11,45-71]$. We concluded that this model would be very useful in several domains of the physical and chemical sciences. In addition, it will be very interesting for engineering data and it will permit estimating one nonavailable parameter when the second one is available ((14) or (15)) or can be moreover evaluated by some theories suggested in the literature [11, 17-21].

We note that the HajKacem-Ouerfelli equation [16] presents a good concordance ( $R$-square 0.9999$)$ only for the low and moderate viscous fluids which have no very high values of activation energy $\left(6<E_{a}<30 \mathrm{~kJ} \cdot \mathrm{mol}^{-1}\right)$ and no very low values of preexperimental factor $(-17<$ $\left.\ln \left(A_{s} / \mathrm{Pa} \cdot \mathrm{s}\right)<-10\right)$. Through the $R$-square value $(0.9606)$, the proposed equation presents practically a good concordance from the low to the high viscous fluids and presents very feeble discrepancy in the two limits of the studied intervals $\left(5<E_{a}<60 \mathrm{~kJ} \cdot \mathrm{mol}^{-1}\right)$ for the activation energy and $(-25$ $\left.<\ln \left(A_{s} / \mathrm{Pa} \cdot \mathrm{s}\right)<-9\right)$ for the preexperimental factor. Then, the present work suggests an empirical exponential law-type equation valid on more extended intervals because we have taken into account some mathematical considerations. We add that the statistical results can be improved when all parameters will be considered as freely adjustable ones.

We hope that this study opens a new interesting field of fruitful investigations such as the study of specific groups or families of organic liquids solvents (acids, hydrocarbon, alcohols, ketones, amides, etc.). It could also open the way to estimate more accurate values of the proposed equation's parameters, when the nature of fluids is classified separately (high, moderate, low viscous liquids) or solvent characteristics (protic, polar, nonpolar, etc.). Thereby, each classified investigation can provide specific parameter values $\left(T_{0}, \alpha_{0}\right.$, and $\left.\gamma_{0}\right)$ especially the limiting Arrhenius temperature $\left(T_{0}\right)$ and it leads to more accurate specific ones with better statistical results, demonstrating how this model deserves validity. In the same way, this correlation may encourage theorists to combine or merge some previously distinct theoretical methods already available. In addition, we hope that it will be useful in large domains of applied physics, chemistry fluid mechanics, and engineering.

We can add that an additional study on the eventual relationship between the viscosity Arrhenius parameters and the properties of numerous different liquid systems can prove how the method predicts the properties of other nonstudied fluid systems. In order to firmly find the utility of the Arrhenius temperature and develop a means for estimating such quantities [12-15, 52, 72-75], more binary liquid mixtures will be studied against composition in the future to give a more clear discussed protocol. To our knowledge, there is no stronger theoretical and physical basis of this study or any developed predictive methods for our initial assumptions and so we will be able to provide more fairly the validation of our empirical equation after the application of our proposed equations by several experimentalists in the future. We are very much hopeful that these original and interesting experimental findings can be equally well received by the experimentalists and the theorists and lead to developing eventual new theoretical approaches. In a future work, we will try to give an extension and validation of the proposed equation for Newtonian binary liquid mixtures obeying the viscosity Arrhenius-type equation at whole range of composition which will also be important in fluid engineering since it allows us to simplify the estimation of viscous behavior of liquid mixtures by reducing the number of viscosity-temperature equation parameters. Also, we will address the mutual causal correlation between the viscosity Arrhenius parameters and the effect of pressure on the viscosity. In particular, we would be interested to find out how the said correlations can be deduced from the available theories.

\section{Conflict of Interests}

The authors declare that there is no conflict of interests regarding any matters with regard to the publication or the coauthors.

\section{References}

[1] N. Ouerfelli, M. Bouaziz, and J. V. Herráez, "Treatment of Herráez equation correlating viscosity in binary liquid mixtures 
exhibiting strictly monotonous distribution," Physics and Chemistry of Liquids, vol. 51, no. 1, pp. 55-74, 2013.

[2] J. V. Herráez, R. Belda, O. Díez, and M. Herráez, "An equation for the correlation of viscosities of binary mixtures," Journal of Solution Chemistry, vol. 37, no. 2, pp. 233-248, 2008.

[3] J. B. Irving, NEL Report Numbers 630 and 631, National Engineering Laboratory, Glasgow, UK, 1977.

[4] S. W. Benson, Thermochemical Kinetics, John Wiley \& Sons, New York, NY, USA, 2nd edition, 1976.

[5] J. A. Dean, Handbook of Organic Chemistry, McGraw-Hill, New York, NY, USA, 1987.

[6] S. Glasstone, K. L. Laidler, and H. Eyring, The Theory of Rate Process, McGraw-Hill, New York, NY, USA, 1941.

[7] L.-S. Lee and Y.-S. Lee, "The application of the equations of state incorporated with mixing rules for viscosity estimations of binary mixtures," Fluid Phase Equilibria, vol. 181, no. 1-2, pp. 47-58, 2001.

[8] L. Qunfang and H. Yu-Chun, "Correlation of viscosity of binary liquid mixtures," Fluid Phase Equilibria, vol. 154, no. 1, pp. 153$163,1999$.

[9] R. Macías-Salinas, F. García-Sánchez, and G. Eliosa-Jiménez, "An equation-of-state-based viscosity model for non-ideal liquid mixtures," Fluid Phase Equilibria, vol. 210, no. 2, pp. 319-334, 2003.

[10] F. B. M. Belgacem, "Diffusion and drift models for population dispersal from stochastic and continuum views," International Journal of Applied Mathematics, vol. 5, no. 1, pp. 85-106, 2001.

[11] D. S. Viswanath, T. K. Ghosh, G. H. L. Prasad, N. V. K. Dutt, and K. Y. Rani, Viscosity of Liquids: Theory, Estimation, Experiment, and Data, Springer, Dordrecht, The Netherlands, 2007.

[12] M. Hichri, D. Das, A. Messaâdi, E. S. B. H. Hmida, N. Ouerfelli, and I. Khattech, "Viscosity Arrhenius activation energy and derived partial molar properties in of $\mathrm{N}, \mathrm{N}$-dimethylacetamide + 2-ethoxyethanol binary mixtures at temperatures from 298.15 K to 318.15 K," Physics and Chemistry of Liquids, vol. 51, no. 6, pp. 721-730, 2013.

[13] D. Das, A. Messaâdi, N. Dhouibi, N. Ouerfelli, and A. H. Hamzaoui, "Viscosity Arrhenius activation energy and derived partial molar properties in N,N-Dimethylacetamide + water binary mixtures at temperatures from 298.15 to 318.15 K,' Physics and Chemistry of Liquids, vol. 51, no. 5, pp. 677-685, 2013.

[14] D. Das, Z. Barhoumi, N. Dhouibi, M. A. M. K. Sanhoury, and N. Ouerfelli, "The reduced Redlich-Kister equations for correlating volumetric and viscometric properties of N,N-dimethylacetamide + dimethylformamide binary mixtures at temperatures from 298.15 to 318.15 K," Physics and Chemistry of Liquids, vol. 50, no. 6, pp. 712-734, 2012.

[15] M. Dallel, D. Das, E. S. Bel Hadj Hmida, N. A. Al-Omair, A. A. Al-Arfaj, and N. Ouerfelli, "Derived partial molar properties investigations of viscosity Arrhenius parameters in formamide + N,N-dimethylacetamide systems at different temperatures," Physics and Chemistry of Liquids, vol. 52, no. 3, pp. 442-451, 2014.

[16] R. Ben Haj-Kacem, N. Ouerfelli, J. Herráez, M. Guettari, H. Hamda, and M. Dallel, "Contribution to modeling the viscosity Arrhenius-type equation for some solvents by statistical correlations analysis," Fluid Phase Equilibria, vol. 383, pp. 11-20, 2014.

[17] J. G. Kirkwood, F. P. Buff, and M. S. Green, "The statistical mechanical theory of transport processes. III. The coefficients of shear and bulk viscosity of liquids," The Journal of Chemical Physics, vol. 17, no. 10, pp. 988-994, 1949.
[18] P. T. Cummings and D. J. Evans, "Nonequilibrium molecular dynamics approaches to transport properties and nonNewtonian fluid rheology," Industrial \& Engineering Chemistry Research, vol. 31, no. 5, pp. 1237-1252, 1992.

[19] H. Eyring, "Viscosity, plasticity, and diffusion as examples of absolute reaction rates," The Journal of Chemical Physics, vol. 4, no. 4, pp. 283-291, 1936.

[20] H. Eyring and J. Hirschfelder, "The theory of the liquid state," Journal of Physical Chemistry, vol. 41, no. 1, pp. 249-257, 1937.

[21] H. Eyring and M. S. John, Significant Liquid Structure, Wiley, New York, NY, USA, 1969.

[22] H. Vogel, "Das Temperaturabhängigkeitsgesetz der Viskosität von Flüssigkeiten," Physikalische Zeitschrift, vol. 22, pp. 645646, 1921.

[23] G. S. Fulcher, "Analysis of recent measurements of the viscosity of glasses," Journal of the American Ceramic Society, vol. 8, no. 6, pp. 339-355, 1925.

[24] G. Tammann and W. Hesse, "Die Abhängigkeit der Viscosität von der Temperature bieunterkühlten Flüssigkeiten," Zeitschrift für Anorganische und Allgemeine Chemie, vol. 156, pp. 245-251, 1926.

[25] J. de Guzman, "Relation between fluidity and heat of fusion," Anales de la Sociedad Española de Física y Química, vol. 11, pp. 353-362, 1913.

[26] E. N. Andrade, "The viscosity of liquids," Nature, vol. 125, no. 3148, pp. 309-310, 1930.

[27] E. N. Andrade, "A theory of the viscosity of liquids-part I," Philosophical Magazine, vol. 17, pp. 497-511, 1934.

[28] E. N. Andrade, "A theory of the viscosity of liquids-part II," Philosophical Magazine, vol. 17, pp. 698-732, 1934.

[29] C. R. Duhne, "Viscosity-temperature correlations for liquids," Chemical Engineering, vol. 86, no. 15, pp. 83-91, 1979.

[30] D. S. Viswanath and G. Natarajan, Databook on Viscosity of Liquids, Hemisphere, New York, NY, USA, 1989.

[31] N. V. K. Dutt and D. H. L. Prasad, Representation of the Temperature Dependence of the Viscosity of Pure Liquids, Private Communication, Chemical Engineering Division, Indian Institute of Chemical Technology, Hyderabad, India, 2004.

[32] L. A. Girifalco, "Temperature dependence of viscosity and its relation to vapor pressure for associated liquids," The Journal of Chemical Physics, vol. 23, no. 12, pp. 2446-2447, 1955.

[33] H. Noureddini, B. C. Teoh, and L. Davis Clements, "Viscosities of vegetable oils and fatty acids," Journal of the American Oil Chemists Society, vol. 69, no. 12, pp. 1189-1191, 1992.

[34] H. Noureddini and D. Zhu, "Kinetics of transesterification of soybean oil," Journal of the American Oil Chemists' Society, vol. 74, no. 11, pp. 1457-1463, 1997.

[35] W. Lang, S. Sokhansanj, and F. W. Sosulski, "Modelling the temperature dependence of kinematic viscosity for refined canola oil," Journal of the American Oil Chemists' Society, vol. 69, no. 10, pp. 1054-1055, 1992.

[36] N. V. K. Dutt, "A simple method of estimating the viscosity of petroleum crude oil and fractions," The Chemical Engineering Journal, vol. 45, no. 2, pp. 83-86, 1990.

[37] N. I. Kopylov, "Modeling viscosity of crude oil," InzhenernoFizicheskii Zhurnal, vol. 3, pp. 97-103, 1960.

[38] R. H. Perry, Perry's Chemical Engineerers' Handbook, McGrawHill, New York, NY, USA, 6th edition, 1984.

[39] E. Goletz Jr. and D. Tassios, "An Antoine type equation for liquid viscosity dependency to temperature," Industrial \& Engineering 
Chemistry Process Design and Development, vol. 16, no. 1, pp. 7579, 1977.

[40] H. Wochnowsky and B. Müssig, "On the viscosity-temperature behavior of organic liquids," Chemistry, vol. 111, pp. 123-131, 1983.

[41] J. Kotas and M. Valešová, "Thermodynamic activation functions of viscous flow of non-polar liquids," Rheologica Acta, vol. 25, no. 3, pp. 326-330, 1986.

[42] A. Gupta, S. K. Sharma, and A. P. Toor, "An empirical correlation in predicting the viscosity of refined vegetable oils," Indian Journal of Chemical Technology, vol. 14, no. 6, pp. 642-645, 2007.

[43] I. Stanciu, "A new viscosity-temperature relationship for vegetable oil," Journal of Petroleum Technology and Alternative Fuels, vol. 3, no. 2, pp. 19-23, 2012.

[44] H. J. V. Tyrrell and K. R. Harris, Diffusion in Liquids, Butterworths, London, UK, 1984.

[45] G. F. de Verteuil, The viscosity of liquids (a) normal octanol at atmospheric pressure (b) an equipment for high pressure [Thesis in Chemical Engineering], The University of British Columbia, Vancouver, Canada, 1958, http://hdl.handle.net/2429/40892.

[46] G. O. Curme and F. Johnston, Viscosity of Aqueous Propylene Glycol Solutions, Reinhold Publishing Corporation, New York, NY, USA, 1952.

[47] G. Czechowski, A. Rabiega, and J. Jadzyn, "The viscous properties of diols. III. 1,2- and 1,4-butanediol in water and 1-pentanol," Zeitschrift fur Naturforschung-Section A, vol. 58, no. 9-10, pp. 569-572, 2003.

[48] I. M. Smallwood, Handbook of Organic Solvent Properties, John Wiley \& Sons, New York, NY, USA, 1996.

[49] D. Das, S. K. Ray, and D. K. Hazra, "Excess molar volumes and viscosity deviations in binary mixtures of N,N-dimethylacetamide with formamide and N,N-dimethylformamide at 298.15 K, 308.15 K and 318.15 K," Journal of the Indian Chemical Society, vol. 80, no. 4, pp. 385-390, 2003.

[50] P. J. Victor, D. Das, and D. K. Hazra, "Excess molar volumes, viscosity deviations and isentropic compressibility changes in binary mixtures of N,N-dimethylacetamide with 2methoxyethanol and water in the temperature range 298.15 to 318.15 K," Journal of the Indian Chemical Society, vol. 81, no. 12, pp. 1045-1050, 2004.

[51] D. Das and D. K. Hazra, "Molecular interaction study in binary mixtures of N,N-dimethylacetamide with 2-ethoxyethanol at three different temperatures," Indian Journal of Physics B, vol. 77, pp. 519-523, 2003.

[52] N. Ouerfelli, Z. Barhoumi, and O. Iulian, "Viscosity Arrhenius activation energy and derived partial molar properties in 1,4dioxane + water binary mixtures from 293.15 to 323.15 K," Journal of Solution Chemistry, vol. 41, no. 3, pp. 458-474, 2012.

[53] N. Ouerfelli and M. Bouanz, "A shear viscosity study of cerium (III) nitrate in concentrated aqueous solutions at different temperatures," Journal of Physics Condensed Matter, vol. 8, no. 16, pp. 2763-2774, 1996.

[54] R. Belda, J. V. Herráez, and O. Diez, "Rheological study and thermodynamic analysis of the binary system (water/ethanol): influence of concentration," Physics and Chemistry of Liquids, vol. 42, no. 5, pp. 467-479, 2004.

[55] S. Z. Mikhail and W. R. Kimel, "Densities and viscosities of methanol-water mixtures," Journal of Chemical \& Engineering Data, vol. 6, no. 4, pp. 533-537, 1961.
[56] O. Ciocirlan and O. Iulian, "Vapor pressure, density, viscosity and refractive index of dimethyl sulfoxide +1,4-dimethylbenzene system," Journal of the Serbian Chemical Society, vol. 73, no. 1, pp. 73-85, 2008.

[57] O. Ciocirlan and O. Iulian, "Density, viscosity and refractive index of the dimethyl sulfoxide + o-xylene system," Journal of the Serbian Chemical Society, vol. 74, no. 3, pp. 317-329, 2009.

[58] O. Iulian and O. Ciocîrlan, "Viscosity and density of systems with water, 1,4-dioxane and ethylene glycol between (293.15 and 313.15) K. I. binary systems," Revue Roumaine de Chimie, vol. 55, no. 1, pp. 45-53, 2010.

[59] N. Hafaiedh, A. Toumi, and M. Bouanz, "Dynamic viscosity study of binary mixtures triethylamine + water at temperatures ranging from (283.15 to 291.35) K," Journal of Chemical \& Engineering Data, vol. 54, no. 8, pp. 2195-2199, 2009.

[60] A. Toumi, N. Hafaiedh, and M. Bouanz, "Thermodynamic properties of triethylamine + water liquid mixture from shear viscosity measurements," Fluid Phase Equilibria, vol. 278, no. 12, pp. 68-75, 2009.

[61] J. B. Segur and H. E. Oberstar, "Viscosity of glycerol and its aqueous solutions," Industrial \& Engineering Chemistry, vol. 43, no. 9, pp. 2117-2120, 1951.

[62] X.-X. Li, G.-C. Fan, Y.-W. Wang, M. Zhang, and Y.-Q. Lu, "Volumetric and viscosimetric properties of the binary mixture of triethylene glycol monomethyl ether + water at $T=(293.15$, 303.15, 313.15, 323.15, 333.15) K under atmospheric pressure," Journal of Molecular Liquids, vol. 151, no. 1, pp. 62-66, 2010.

[63] C. K. Zéberg-Mikkelsen, G. Watson, A. Baylaucq, G. Galliéro, and C. Boned, "Comparative experimental and modeling studies of the viscosity behavior of ethanol + C7 hydrocarbon mixtures versus pressure and temperature," Fluid Phase Equilibria, vol. 245, no. 1, pp. 6-19, 2006.

[64] S. Akhtar, M. M. H. Bhuiyan, M. S. Uddin, B. Sultana, M. Nessa, and M. A. Saleh, "Viscosity of aqueous solutions of some alcohols," Physics and Chemistry of Liquids, vol. 37, no. 3, pp. 215-227, 1999.

[65] S. Parthasarathi, K. Saravanakuamr, R. Baskaran, and T. R. Kubendran, "A volumetric and viscosity study for the binary mixtures of dimethylsulfoxide with benzene, ethyl benzene, chlorobenzene and bromobenzene at temperatures of (303.15, 308.15 and 313.15) K and a pressure of 0.1 MPa," The International Journal of Science \& Technology, vol. 1, pp. 96-101, 2011.

[66] A. Omrani, A. A. Rostami, and M. Mokhtary, "Densities and volumetric properties of 1,4-dioxane with ethanol, 3-methyl-1butanol, 3-amino-1-propanol and 2-propanol binary mixtures at various temperatures," Journal of Molecular Liquids, vol. 157, no. 1, pp. 18-24, 2010.

[67] P. J. Victor and D. K. Hazra, "Excess molar volumes, viscosity deviations, and isentropic compressibility changes in binary mixtures of $\mathrm{N}$-methylacetamide +2 -methoxyethanol and $\mathrm{N}$ methylacetamide + water at $(308.15,313.15$, and 318.15) K," Journal of Chemical \& Engineering Data, vol. 47, no. 1, pp. 79-82, 2002.

[68] P. K. Muhuri and D. K. Hazra, "Density and viscosity of propylene carbonate +2 -methoxyethanol at 298.15, 308.15, and 318.15 K," Journal of Chemical \& Engineering Data, vol. 40, no. 3, pp. 582-585, 1995.

[69] P. K. Muhuri and D. K. Hazra, "Density and viscosity for propylene carbonate +1 ,2-dimethoxyethane at 298.15, 308.15, and $318.15 \mathrm{~K}$, 'Journal of Chemical and Engineering Data, vol. 39, no. 2, pp. 375-377, 1994. 
[70] N. Saha, B. Das, and D. K. Hazra, "Viscosities and excess molar volumes for acetonitrile + methanol at 298.15, 308.15, and 318.15 K,' Journal of Chemical \& Engineering Data, vol. 40, no. 6, pp. 1264-1266, 1995.

[71] P. K. Muhuri, B. Das, and D. K. Hazra, "Viscosities and excess molar volumes of binary mixtures of propylene carbonate with tetrahydrofuran and methanol at different temperatures," Journal of Chemical \& Engineering Data, vol. 41, no. 6, pp. 14731476, 1996.

[72] Z. Trabelsi, M. Dallel, H. Salhi, D. Das, N. Al-Omair, and N. Ouerfelli, "On the viscosity Arrhenius temperature for methanol $+\mathrm{N}, \mathrm{N}$-dimethylformamide binary mixtures over the temperature range from 303.15 to $323.15 \mathrm{~K}$," Physics and Chemistry of Liquids, vol. 53, no. 4, pp. 529-552, 2015.

[73] N. Dhouibi, M. Dallel, D. Das, M. Bouaziz, N. Ouerfelli, and A. Hamzaoui, "Notion of viscosity Arrhenius temperature for $\mathrm{N}, \mathrm{N}$-dimethylacetamide with $\mathrm{N}, \mathrm{N}$-dimethylformamide binary mixtures and its pure components," Physics and Chemistry of Liquids, vol. 53, no. 2, pp. 275-292, 2014.

[74] H. Salhi, M. Dallel, Z. Trabelsi, N. O. Alzamil, M. A. Alkhaldi, and N. Ouerfelli, "Viscosity Arrhenius activation energy and derived partial molar properties in methanol $+N, N$-dimethylacetamide binary mixtures the temperatures from $298.15 \mathrm{~K}$ to 318.15 K," Physics and Chemistry of Liquids, vol. 53, no. 1, pp. 117137, 2014.

[75] A. Messaâdi, H. Salhi, D. Das et al., "A novel approach to discuss the Viscosity Arrhenius behavior and to derive the partial molar properties in binary mixtures of N,N-dimethylacetamide with 2-methoxyethanol in the temperature interval (from 298.15 to 318.15) K," Physics and Chemistry of Liquids, vol. 53, no. 4, pp. 506-517, 2015. 

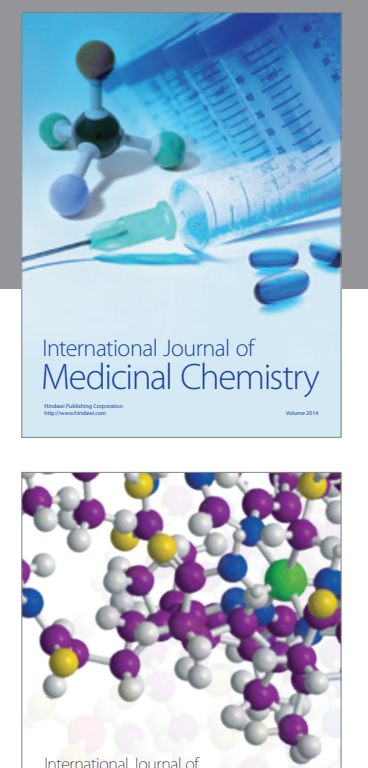

\section{Carbohydrate} Chemistry

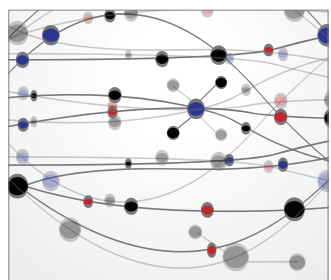

The Scientific World Journal
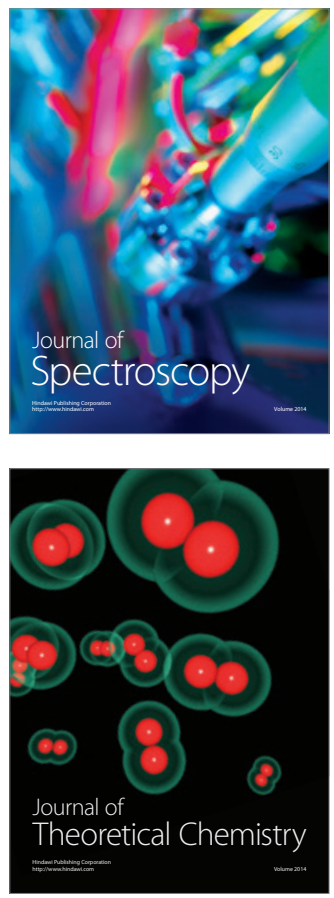
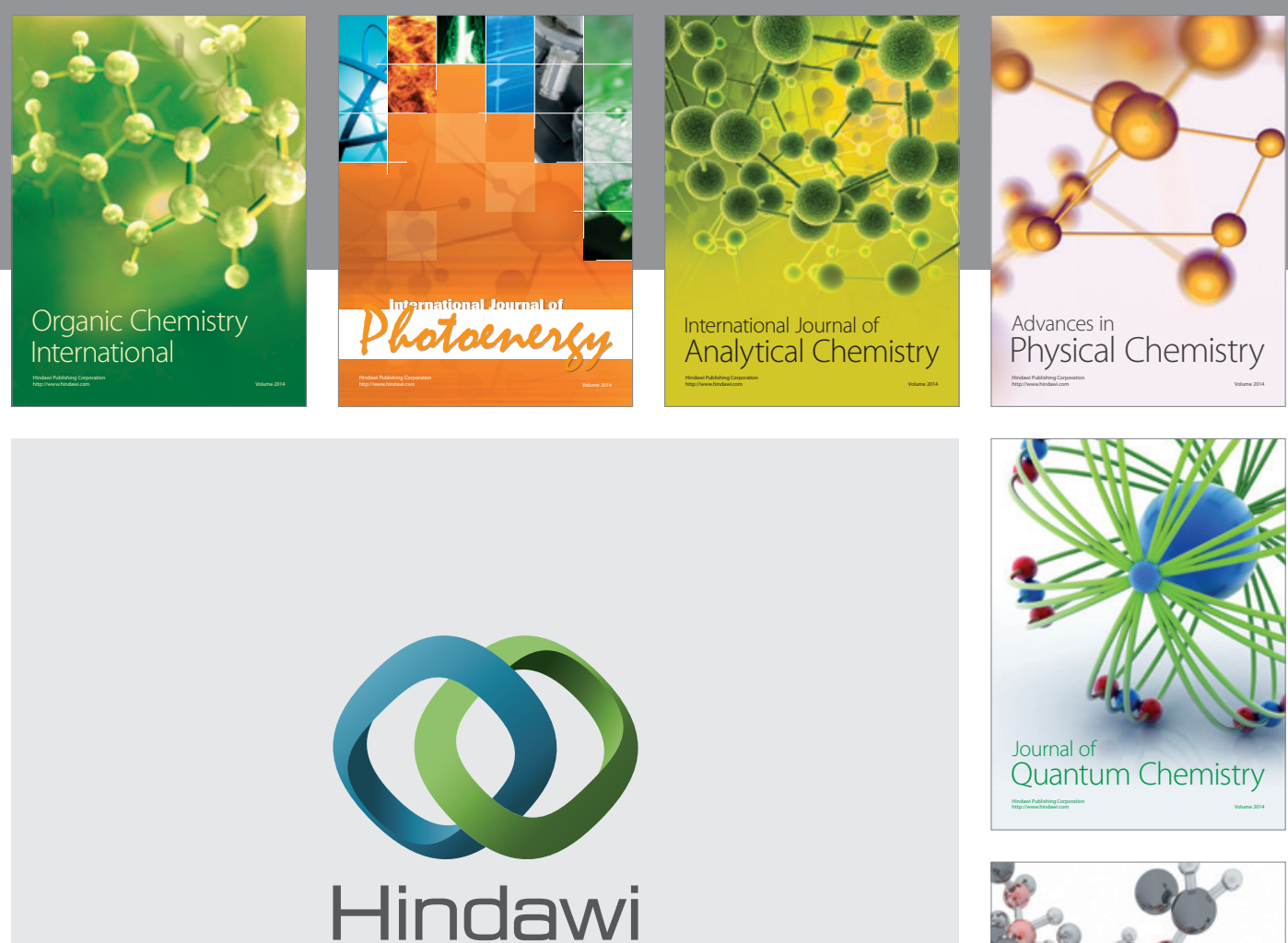

Submit your manuscripts at

http://www.hindawi.com

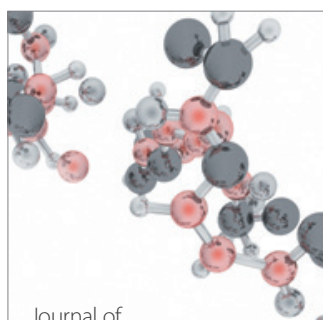

Analytical Methods

in Chemistry

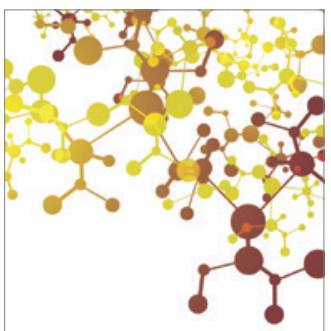

Journal of

Applied Chemistry

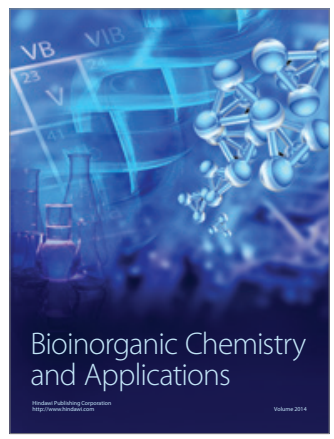

Inorganic Chemistry
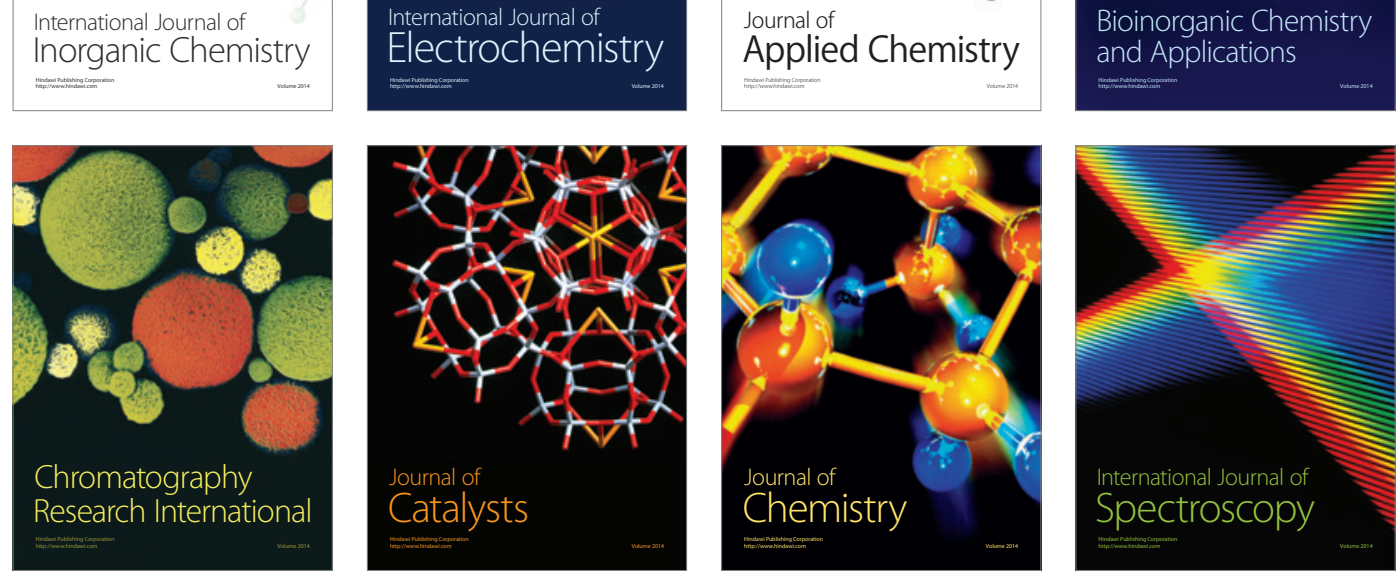